\title{
Social Support, Self-efficacy, Self-esteem, and Well-being During COVID-19 Lockdown: A Two-wave Study of Danish Students
}

\author{
Simon Ozer \\ Department of Psychology and Behavioural Sciences, Aarhus University, Bartholins Allé 11, 8000 \\ Aarhus C, Denmark \\ E-mail address: ozer@psy.au.dk
}

This working paper has not yet been peer reviewed. Date: January 12, 2022

Wordcount: 4725 (excluding references, tables, and figures) 


\begin{abstract}
Societal lockdown due to the COVID-19 pandemic has transformed everyday life across the globe, including requirements of social distancing which might limit the social support people derive from social interaction. Social support has proven to be a vital resource for well-being and coping during societal challenges. The present study examines how social support is associated with perceived stress and life satisfaction through self-efficacy and self-esteem among Danish students $(N=204)$. These psychological constructs were examined both during and after lockdown, assessing the possible aversive psychological effects of the COVID-19 pandemic. Results did not yield any significant changes in either the mean scores of the constructs or the indirect effects model across the two timepoints. Moreover, the results indicate that social support derived from a significant person, family, and friends - but not student peers - is negatively linked with perceived stress and positively associated with life satisfaction through both self-efficacy and self-esteem. Although societal lockdown did not yield significant psychological impact, the results highlight the importance of social support among students, both during and after lockdown.
\end{abstract}

Keywords: COVID, Social Support, Well-being, Self-efficacy, Self-esteem, Students

Social Support, Self-efficacy, Self-esteem, and Well-being During COVID-19 Lockdown: A Two-wave Study of Danish Students 


\section{Introduction}

The SARS CoV-2 virus (hereafter, COVID-19) has initiated a global pandemic that constitutes a threat to public health and poses a strong impact on people's everyday life, including challenges associated with managing this health threat such as social distancing, societal restrictions, and lockdowns. As a preventive measure, the World Health Organization (2021) proposed social distancing and avoiding large gatherings. These guidelines were configured into national restrictions and periodic lockdowns; consequently, many people have experienced an elevated level of uncertainty, anxiety, and stress during the pandemic (Mai et al., 2021). Specifically, fear of COVID-19 has been associated with a greater level of anxiety, depression, and stress in one metaanalysis (Şimşir et al., 2021). Overall, meta-reviews of 18 meta-analyses revealed high proportions of psychophysiological stress in the general population (de Sousa et al., 2021).

Students navigating important life phases focused on developing a sense of direction and of sense of self have been strongly affected by the COVID-19 pandemic. One study in the US indicated that $13 \%$ of students have delayed graduation because of the pandemic, among other negative effects (Aucejo et al., 2020). The COVID-19 lockdowns meant that physical attendance at universities in Denmark and in other countries was periodically prohibited and lectures were moved online. That is, universities were abruptly converted into virtual learning environments often excluding various forms of non-informal social interaction. Because of restrictions on social contact emphasizing social distancing, social support has emerged as a central factor vis-à-vis psychological well-being during the pandemic (Szkody et al., 2020).

Social support has in research emerged as an important resource that can protect the individual during stressful situations (Cassel, 1976; Szkody et al., 2020). Specifically, social support has 


\section{SOCIAL SUPPORT AND WELL-BING DURING COVID LOCKDOWN}

proven an important factor in mitigating students' psychological distress during COVID-19 (Li et al., 2021). Moreover, the association between social support and psychological adaptation is partly mediated by students' level of self-efficacy, which reflects how social resources form beliefs about one's ability to handle stressors (Saltzman \& Holahan, 2002). Social support also plays a pivotal role in students' academic life in regard to academic achievement and emotional exhaustion mediated by self-esteem. This indicates how social relations can elevate students' experience of being valued and accepted and in turn elevate their well-being (Li et al., 2018). In the present

study, students' level of perceived social support, self-efficacy, self-esteem, and psychological wellbeing was assessed during COVID-19 lockdown and after the reopening of society. Moreover, an indirect effects model examined how social support was associated with perceived stress and life satisfaction through self-esteem and self-efficacy across these two timepoints. The aim of the study was to assess the psychological impact of COVID-19 lockdown on students, specifically regarding the important role of social support during a societal crisis.

\section{Social Support and Well-being}

Social support has been hypothesized as a protective resource against negative and stressful events. Indeed, social support can make the individual feel more in control of the situation and capable of processing negative events, which in turn can buffer against negative impacts to one's well-being (Cassel, 1976). Besides reducing the impact of negative events on mental health, social support has been directly associated with well-being, which suggests that lack of social support and changes in support over time can act as stressors themselves (Thoits, 1985).

Social support has been conceptualized as an exchange of resources among individuals, and that exchange is understood to enhance the well-being of the recipient (Shumaker \& Brownell, 1984). That is, the primary function of social support is to inform the individual that he or she is 


\section{SOCIAL SUPPORT AND WELL-BING DURING COVID LOCKDOWN}

cared for and esteemed, and that he or she belongs to a mutually obliging network (Callaghan \& Morrisey, 1993). Accordingly, the experience of social support has a strong impact on selfperception affecting one's level of well-being (Friedlander et al., 2007).

Students derive beneficial social support from parents, friends, and peers, each of whom provides guidance, feedback, and non-directive support; this makes possible positive social interaction, which in turn enhances one's level of well-being (Friedlander et al., 2007). Empirical research has found that students' level of perceived social support was protective against social distancing during COVID-19 and mitigated students' level of anxiety and stress (Szkody et al., 2020). Accordingly, social support appears to perform a vital role in navigating crisis-initiated aloof student life, and a decrease in social support would then negatively affect students' well-being.

\section{Socially Derived Confidence and Sense of Personal Worth during COVID-19}

Although the psychological constructs of self-efficacy and self-esteem both concern cognition and self-perception, they are distinct in the sense that self-efficacy describe one's optimistic perception of one's competence beliefs and confidence (Bandura, 1997), whereas self-esteem reflects the affective evaluation of one's self-worth (Rosenberg, 1965). Accordingly, self-efficacy can be regarded as a positive resistance and resource factor when coping with adversity (Schwarzer \& Jerusalem, 1995). Additionally, self-esteem has been associated with coping in research reflecting how people with low levels of self-esteem relied on emotion-based coping strategies, while people with high levels of self-esteem relied on beneficial coping strategies directed at problem solving (Moos, 1990).

Research indicates that both self-efficacy and self-esteem are shaped by social relations. Bandura (1997) described mastery experiences as a primary source for self-efficacy. Additionally, watching others perform tasks and comparing others' and own abilities, as well as receiving 


\section{SOCIAL SUPPORT AND WELL-BING DURING COVID LOCKDOWN}

encouragement from other people, reflect how social support can shape the individual's sense of self-efficacy. Because of the detrimental effects of being ostracized, people strive to maintain interpersonal relationships; consequently, self-esteem fluctuates as a function of the person's perception of being valued and accepted by others, i.e., social support (Leary, 1999). Harris and Orth (2019) have found empirical support for the association between social relationships and selfesteem in their meta-analysis of longitudinal studies of this topic. In research, self-efficacy and selfesteem are consequential psychological concepts regarding student life, and both have been strongly associated with students' achievement and with self-regulation and motivation (Bartimote-Aufflick et al., 2016; Li et al., 2018).

Regarding the COVID-19 pandemic, research has revealed that the higher degree of perceived social support (e.g., emotional support from family and friends and/or perceived help from teachers and classmates) the more likely students are to adopt positive coping strategies and thus improve their mental health (Mai et al., 2021). Cognitive resources such as self-efficacy and self-esteem may help students cope with pandemic-related psychological challenges associated with disrupted student life and limited social interaction. That is, confidence in one's ability to execute necessary behavior and performance as well as one's perception of abilities and limitations emerge as important internal resiliency factors during an international health crisis and these aspects of selfperception are shaped by social support. For example, academic self-efficacy has been negatively associated with anxiety level among students during the critical events of COVID-19 (AlemanyArrebola et al., 2020). Furthermore, confirming the anxiety-buffer hypothesis, self-esteem has been found to mediate the relationship between loneliness and psychological distress during COVID-19 (Rossi et al., 2020). That is, a decrease in social support might negatively affect student's selfperception as a coping resource, and that could in turn deteriorate their well-being during COVID19. 


\section{Current Study}

The study was preregistered at (https://osf.io/e6js7/?view_only=2195f81670974cf6a825ca938f51bebd ). Within this study, mean levels as well as the relationships among social support, self-efficacy, self-esteem, perceived stress, and life satisfaction were examined in regard to longitudinal changes in a student sample across societal lockdown and the reopening of society. Based on the literature review, the relationships between variables were hypothesized through an indirect effects model (Figure 1). Accordingly, the following four hypotheses were tested:

H1: Perceived social support was hypothesized to be lower during as compared to after lockdown resulting in likewise lower levels of self-efficacy, self-esteem, and life satisfaction as well as a higher level of perceived stress during COVID-19 lockdown.

$\mathrm{H} 2$ : Social support was expected to be negatively associated with perceived stress through selfefficacy and self-esteem.

H3: Social support was expected to be positively associated with life satisfaction through selfefficacy and self-esteem.

H4: The association between social support and the other variables was hypothesized to be stronger during as compared to after lockdown, reflecting social support as a vital resource in the face of a crisis. 
Figure 1. The hypothesized indirect effects model.

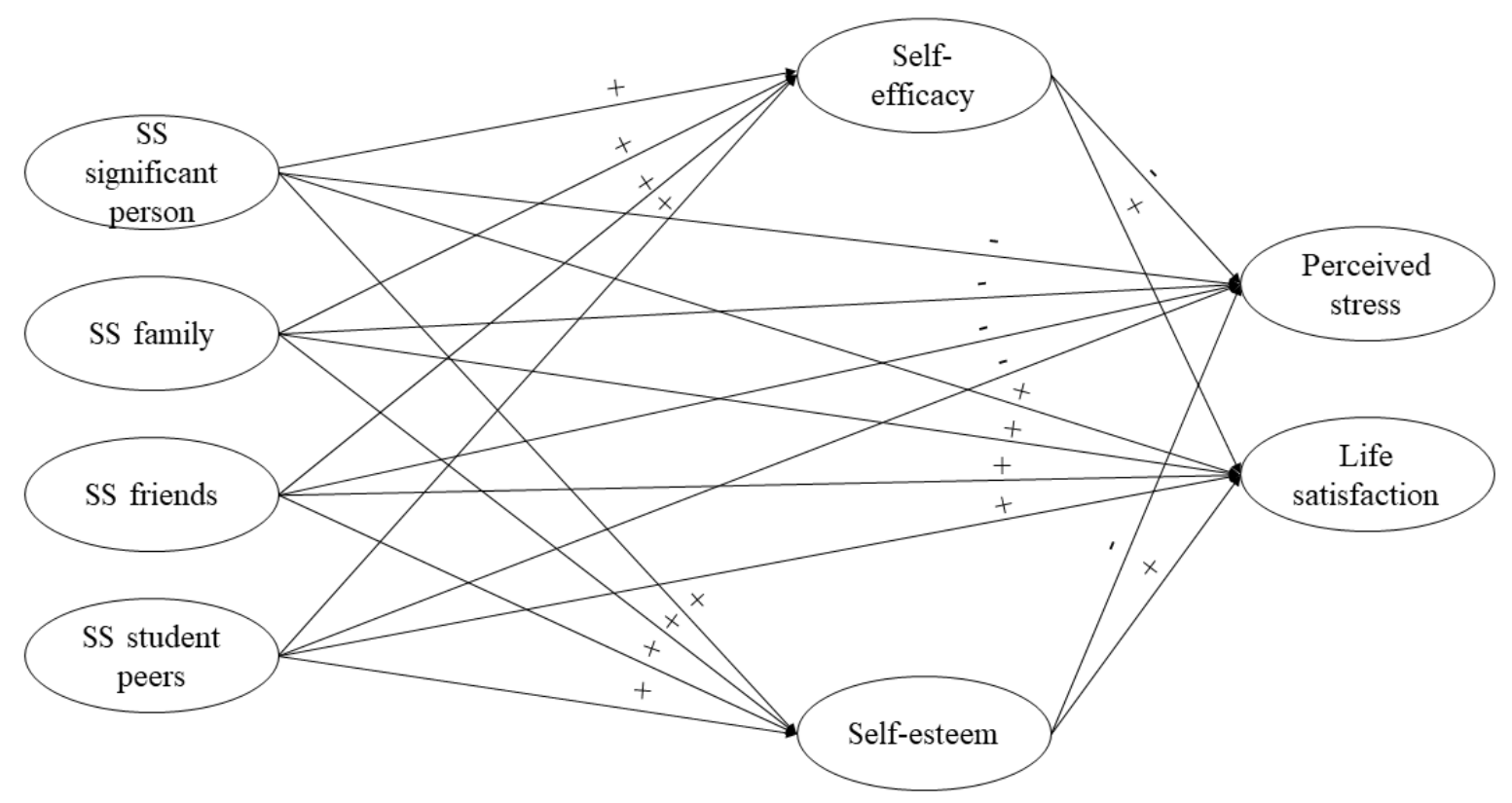

Method

Students in Denmark were invited to the study through mailing lists as well as through student Facebook groups. E-mail addresses were anonymously collected and used for distributing invitations to the second part of the study. The data that support the study findings are available from the corresponding author upon reasonable request.

\section{Participants}

Using $G^{*}$ Power, a power analysis was conducted for a two-tailed paired sample t-test to detect a small effect $(f=.20)$ with a power of 0.80 . This power analysis indicated a minimum required sample size of $N=199$ to detect significant effects (alpha level of .05) given the existence of a true effect. Anticipating the risk of a $30 \%$ dropout rate between the two data collections, at least 259 participants are needed. 


\section{SOCIAL SUPPORT AND WELL-BING DURING COVID LOCKDOWN}

A total of 338 students completed the online questionnaire at T1 (between February 23 and March 7 in 2021) during lockdown, whereas only 207 participated in T2 (between September 23 and October 27 in 2021) after the lockdown was lifted. Eventually, it was possible to match the replies from 204 students to constitute the final sample used in the analyses. There were no significant mean differences in all variables between students who completed only T1 and students who completed both $\mathrm{T} 1$ and $\mathrm{T} 2$.

The final sample of 204 Danish students $\left(M_{\text {age }}=24.13, S D=3.60\right)$ consisted of $82.4 \%$ female, $17.2 \%$ male, and $0.5 \%$ did not wish to answer the question. Among the students, $36.3 \%$ studied health, $27 \%$ social science, $25 \%$ humanities, $8.3 \%$ natural science, $1 \%$ business, and $2.5 \%$ other. Twenty-four percent were first-year students, $20.6 \%$ were second-year students, $20.1 \%$ were thirdyear students, $14.7 \%$ were fourth-year students, $10.3 \%$ were fifth-year students, and $10.3 \%$ had been studying for more than 5 years. Regarding SES, $14.7 \%$ reported a family income above average, $30.9 \%$ just above average, $35.3 \%$ average, $11.3 \%$ just below average, and $7.8 \%$ below average.

\section{Measurement}

Besides questions regarding background information, the following measurement scales were employed (see Table 1 for internal consistency):

Social Support. Multidimensional Scale of Perceived Social Support (Zimet et al., 1988) is a 12-item measure of social support from (1) significant others, (2) family, and (3) friends. The present study included an additional four items tapping into the social support attained from student peers. Sample items include: "I can talk about my problems with my family," and "I can actively discuss class material with my fellow students." Responses were provided on a 7-point Likert scale ranging from 1 (Strongly disagree) to 7 (Strongly agree). 
Self-efficacy. General Self-Efficacy Scale (GSE; Schwarzer, \& Jerusalem, 1995) measures the individuals' belief in their ability to achieve goals. A sample item reads, "I can usually handle whatever comes my way." Responses were provided on a 4-point Likert scale ranging from 1 (Not at all true) to 4 (Exactly true).

Self-esteem. The Rosenberg Self-Esteem Scale (RSES; Rosenberg, 1965) measures both positive and negative feelings about the self through ten items that ask for reflections on the participant's current feelings. A sample prompt reads, "I wish I could have more respect for myself.” Responses were provided on a 4-point Likert scale ranging from 1 (Strongly agree) to (Strongly disagree).

Perceived Stress. The Perceived Stress Scale (Cohen et al., 1983) measures the perception of stress by tapping into the experience of unpredictability, uncontrollability, and overload in one's life as experienced during the last month. The scale consists of 10 items, including: "In the last month, how often have you found that you could not cope with all the things that you had to do?" Responses were provided on a 5-point Likert scale ranging from 1 (Never) to 5 (Very often).

Life Satisfaction. Satisfaction with Life Scale (SWLS; Diener et al., 1985) is a five-item measure of global life satisfaction. Sample items include, "So far I have gotten the important things I want in life." Responses were provided on a 7-point Likert scale ranging from 1 (Strongly disagree) to 7 (Strongly agree).

\section{Analytic Approach}

The mean changes in all variables (H1) were evaluated through a paired sample t-test in SPSS. The relationship between the variables (i.e., the hypothesized indirect effects model reflecting $\mathrm{H} 2$ and H3) were examined through SEM analysis in Mplus 8 (Muthén \& Muthén, 1998-2011) employing Maximum Likelihood estimation with robust standard errors. The following criteria 
were employed for evaluating model fit: $\chi^{2} / \mathrm{df}$ ratio must be less than 3 (Schermelleh-Engel et al., 2003), Comparative Fit Index (CFI) $\geq .90$, Root Mean Square Error of Approximation (RMSEA) $\leq$ .08 , and Standardized Root Mean Square Residual $($ SRMR) $\leq .08$ for acceptable fit (Kline, 2015). The chi-square evaluates the null hypothesis of perfect fit between the model and the data; the CFI indexes the extent to which the specified model represents an improvement over a null model with no paths or latent variables; the RMSEA evaluates the extent to which the covariance structure that the model implies deviates from the covariance structure observed in the data; and the SRMR is an absolute measure of fit that is defined as the standardized difference between the observed and predicted covariances among study variables. Changes in the relationships between the variables (H4) across the time point condition (i.e., lockdown and reopening of society) were examined through model equivalence comparison by constraining regression paths and evaluating the changes in model fit. Accordingly, the results for T1 and T2 were statistically compared using Little's (2013) criteria for invariance: $\Delta \chi 2$ should not be significant, $\Delta \mathrm{CFI} \leq .010 ; \Delta \mathrm{RMSEA} \leq .010$, and $\Delta \mathrm{SRMR} \leq$ .010.

\section{Results}

The correlation matrix showed the expected relationships between the variables with nearly all variables being significantly correlated and only perceived stress being negatively associated with the other variables (see Table 1).

\begin{tabular}{lllllllllllll}
\multicolumn{10}{l}{ Table 1. Correlation matrix, means, and statistical comparison } \\
\hline
\end{tabular}




\section{Comparison across the Two Timepoints}

The result of the paired samples t-test indicated that neither of the measured variables yielded any significant change across $\mathrm{T} 1$ and $\mathrm{T} 2$ (see Table 1 for results). Reflecting a very small effect size $(d=.13)$, perceived stress was the only variable that approached significance $(p=.070)$, reflecting a small decrease in the reported level of stress from $\mathrm{T} 1(M=2.82 ; S D=0.71)$ to $\mathrm{T} 2(M=2.69 ; S D=$ $0.72)$.

\section{Structural Equation Model}

Multi-group SEM was performed to evaluate the hypothesized indirect effects model at both timepoints employing latent variables for all constructs (all factor loadings ranging between .47 and .95). Within this model, gender and age were controlled for vis-à-vis their effects on the mediating and outcome variables. Additionally, four pairs of similarly worded items were allowed to covary. The model yielded acceptable fit to the data, $\chi^{2}(2658)=3963.32, p<.001 ; \chi^{2} / \mathrm{df}=1.49 ; \mathrm{CFI}=.900$; RMSEA $=.049,95 \%$ CI $(.046 ; .052) ; \mathrm{SRMR}=.066$.

Results (see Figure 2) indicated that social support derived from a significant person was significantly and positively linked with life satisfaction both during the lockdown $(\beta=.27, p<.001$, $95 \% \mathrm{CI}=.14$ to .40$)$ and after lockdown $(\beta=.19, p=.008,95 \% \mathrm{CI}=.05$ to .34$)$ as well as selfesteem both during the lockdown $(\beta=.29, p=.001,95 \% \mathrm{CI}=.13$ to .46$)$ and after lockdown $(\beta=$ $.15, p=.033,95 \% \mathrm{CI}=.01$ to .29$)$. Social support derived from family was significantly associated with self-efficacy during lockdown $(\beta=.27, p=.001,95 \% \mathrm{CI}=.11$ to .43$)$ but not after lockdown $(\beta=.14, p=.073,95 \% \mathrm{CI}=-.01$ to .30$)$. Furthermore, social support from family was significantly and positively related to self-esteem both during lockdown $(\beta=.28, p<.001,95 \% \mathrm{CI}=.14$ to .42$)$ and after lockdown $(\beta=.18, p=.007,95 \% \mathrm{CI}=.05$ to .32$)$. Social support derived from friends was significantly and positively associated with perceived stress after $(\beta=.18, p=.023,95 \% \mathrm{CI}=$ 


\section{SOCIAL SUPPORT AND WELL-BING DURING COVID LOCKDOWN}

.02 to .29$)$ but not during lockdown $(\beta=.02, p=.812,95 \% \mathrm{CI}=-.12$ to .15$)$. Moreover, social support from friends was significantly and positively linked with self-efficacy after $(\beta=.35, p<$ $.001,95 \% \mathrm{CI}=.17$ to .53$)$ but not during lockdown $(\beta=.05, p=.727,95 \% \mathrm{CI}=-.22$ to .32$)$ and similarly associated with self-esteem after $(\beta=.34, p<.001,95 \% \mathrm{CI}=.17$ to .52$)$ but not during lockdown $(\beta=.04, p=.682,95 \% \mathrm{CI}=-.16$ to .25$)$.

Self-efficacy was significantly and negatively linked with perceived stress both during $(\beta=$ $.28, p=.004,95 \% \mathrm{CI}=-.47$ to -.09$)$ and after lockdown $(\beta=-.45, p<.001,95 \% \mathrm{CI}=-.62$ to -.29$)$. Additionally, self-efficacy was positively linked with life satisfaction after $(\beta=.22, p=.008,95 \%$ $\mathrm{CI}=.06$ to .38$)$ but not during lockdown $(\beta=.12, p=.132,95 \% \mathrm{CI}=-.04$ to .28$)$. Self-esteem was significantly and negatively related to perceived stress both during $(\beta=-.47, p<.001,95 \% \mathrm{CI}=-$ .67 to -.27$)$ and after lockdown $(\beta=-.41, p<.001,95 \% \mathrm{CI}=-.60$ to -.22$)$. Furthermore, self-esteem was significantly and positively associated with life satisfaction both during $(\beta=.50, p<.001,95 \%$ $\mathrm{CI}=.33$ to .66$)$ and after lockdown $(\beta=.51, p<.001,95 \% \mathrm{CI}=.34$ to .67$)$.

Figure 2. Results for the hypothesized indirect effects model.

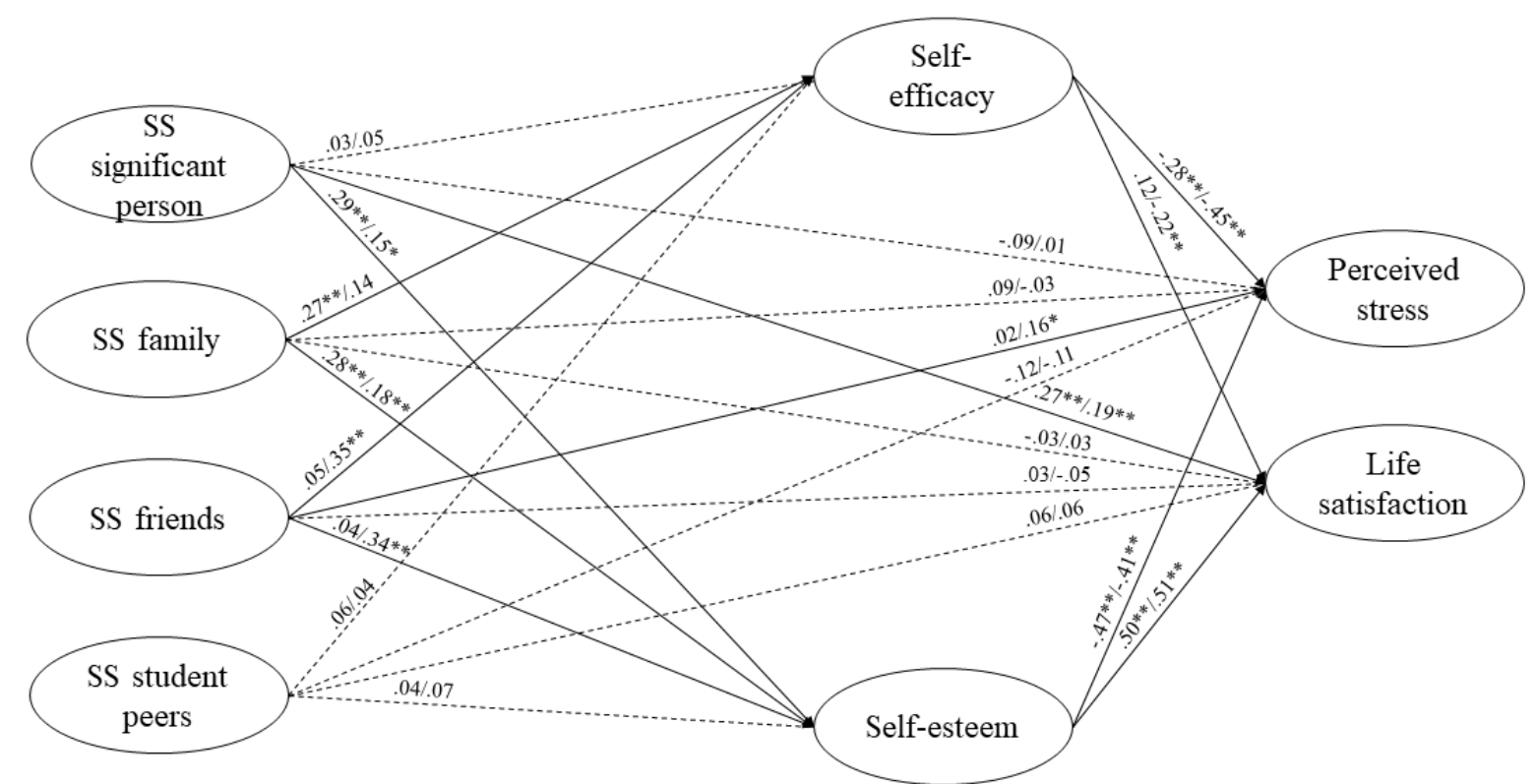

Note. ${ }^{*} p<.05 ; * * p<.01$. Model. Path coefficients reflect T1/T2. In this model self-efficacy and self-esteem were correlated, $r_{\mathrm{T} 1}=.59 ; r_{\mathrm{T}}=.55$. 


\section{Indirect Effects}

Evaluating the indirect effects within the hypothesized model yielded five significant indirect paths in the T1 model and seven indirect paths in the T2 model. Within the T1 model, social support derived from a significant person was indirectly and negatively associated with perceived stress ( $\beta$ $=-.14, p=.009,95 \% \mathrm{CI}=-.24$ to -.03$)$ and positively linked with life satisfaction $(\beta=.15, p=.003$, $95 \% \mathrm{CI}=.05$ to .24$)$ through self-esteem. Social support from family was indirectly and negatively related with perceived stress through self-efficacy $(\beta=-.08, p=.028,95 \% \mathrm{CI}=-.14$ to -.01$)$ and self-esteem $(\beta=-.13, p=.004,95 \% \mathrm{CI}=-.22$ to -.04$)$, while there was also a positive link with life satisfaction through self-esteem $(\beta=.14, p=.001,95 \% \mathrm{CI}=.07$ to .22$)$.

Within T2, social support derived from a significant person was indirectly and positively associated with life satisfaction through self-esteem $(\beta=.08, p=.044,95 \% \mathrm{CI}=.00$ to .15$)$. Social support from family was indirect and negatively related with perceived stress $(\beta=-.08, p=.030$, $95 \% \mathrm{CI}=-.14$ to -.01$)$ and positively to life satisfaction $(\beta=.09, p=.017,95 \% \mathrm{CI}=.02$ to .17$)$ through self-esteem. Moreover, social support from friends was indirectly and negatively linked with perceived stress through self-efficacy $(\beta=-.16, p=.004,95 \% \mathrm{CI}=-.27$ to -.05$)$ and selfesteem $(\beta=-.14, p=.006,95 \% \mathrm{CI}=-.24$ to -.04$)$ and positively associated with life satisfaction through both self-efficacy $(\beta=.08, p=.039,95 \% \mathrm{CI}=.00$ to .15$)$ and self-esteem $(\beta=.17, p=$ $.001,95 \% \mathrm{CI}=.07$ to .28$)$.

\section{Model Equivalence}

Model invariance across the two timepoints (i.e., during and after lockdown) was then examined by comparing constrained (regression paths constrained to be equal across both $\mathrm{T} 1$ and T2) versus unconstrained models (all regression paths freely estimated for both $\mathrm{T} 1$ and $\mathrm{T} 2$ ). The results yielded no significant decrease in model fit; consequently, invariance across the two models 
was established, $\Delta \chi 2(28)=27.52, p=.490 ; \Delta$ CFI $<.001 ; \Delta$ RMSEA $<.001 ; \Delta$ RMSEA $=.007$. That is, no significant change in the overall model emerged during the period of lockdown until after lockdown.

\section{Discussion}

In the present analyses, social support (i.e., derived from significant other, family, friends, and student peers) was examined in relation to perceived stress and life satisfaction through selfefficacy and self-esteem. Additionally, the psychological impact of COVID-19 societal lockdown was assessed among a student sample in a two-wave longitudinal perspective. Hypothesis 1 was not supported, as social support and in turn self-conception and well-being did not significantly change from during lockdown until the reopening of society. Hypotheses 2 and 3 were supported, as social support was negatively associated with perceived stress and positively linked with life satisfaction through self-efficacy and self-esteem. However, social support derived from student peers did not exert any significant effect in the indirect effects model. Hypothesis 4 was not supported, as the indirect effects model was consistent across the two timepoints.

The results indicating non-significant psychological effects from COVID-19 lockdown differ from other findings. For example, research from Spain identified strong psychological impacts among students due to COVID-19 lockdown (Odriozola-González et al., 2020). Research on psychological effects of the ongoing COVID-19 pandemic have often relied on cross-sectional data, which limits the possibility of examining longitudinal effects. In a longitudinal addition to the Spanish study, the levels of stress, anxiety, and depression increased when lockdown measures were relaxed due to accumulative negative effects of the COVID-19 pandemic (Planchuelo-Gómez et al., 2020). The data for this two-wave longitudinal Spanish study was collected with approximately one month between the two surveys, unlike the six-month span used in the present study. Longitudinal 


\section{SOCIAL SUPPORT AND WELL-BING DURING COVID LOCKDOWN}

research form China (Wang et al., 2020) did not find significant changes regarding stress, anxiety, and depression. However, participants in the study by Wang et al, (2020) scored significantly less PTSD symptoms at the peak of the first wave of COVID-19 as compared to the time of the initial outbreak. These results suggest that psychological effects of the COVID-19 pandemic are inconsistent across context and perhaps across population groups. Furthermore, a strong impact could be associated with the outbreak of COVID-19, and the general mental health status might deteriorate during the tedious continuation of the international crisis. This could relate to the present results in that the psychological impact of COVID-19 and societal lockdown might be stronger during the outbreak of the first wave rather than during the second lockdown and the subsequent reopening of society as captured in the present study. Accordingly, the psychological effects of reopening society might differ strongly in strength from the initial effects of closing society. Indeed, longitudinal research has found that mental health and well-being were especially affected in the initial phase of the COVID-19 pandemic (O'Connor et al., 2021, Sibley et al., 2020).

The social support experienced during the COVID-19 pandemic could be achieved in mediated forms. That is, social media and online university activities might facilitate a sense of support from others that can mitigate the adversative effects of restricted real life social interaction. Interestingly, research in China found that perceived social support strongly increased from pre-pandemic stage until the peak of COVID-19 and stabilized at the decline of COVID-19 in society (Xu et al., 2020). This finding was explained by people's wish to resist anxiety, which could make them increasingly engage in social interaction and acquire social support in various forms. These perspectives could suggest that the students in the present study are resourceful in utilizing the accessible channels of support (e.g., social media and online learning platforms). Consequently, less resourceful individuals might struggle more with a lockdown-induced decrease in social support. Research in the US found great heterogeneity in the effects of the pandemic, with lower-income students being 


\section{SOCIAL SUPPORT AND WELL-BING DURING COVID LOCKDOWN}

$55 \%$ more likely to delay graduation due to COVID-19 as compared to high-income students (Aucejo et al., 2020).

A great amount of research examining the effects of the COVID-19 pandemic on mental health and well-being has been rapidly produced to provide immediate results that can assist the public and authorities in understanding and handling the psychological consequences of the pandemic. However, caution has been suggested when evaluating the results (Nieto et al., 2020). Not all research meets rigorous methodological requirements, and many studies are based on crosssectional data that limits the developmental perspective of how the COVID-19 pandemic affects mental health and well-being. Relying solely on prevalence studies might invalidly elevate these effects. Although several hypotheses were not supported by the results of the present study, null findings are important for increasing the confidence in the accuracy of our cumulative knowledge and avoiding publication bias (Kepes et al., 2014).

Self-efficacy and self-esteem emerge as related concepts referring to the individual's conception and sense of self. In the present results, social support derived from friends and/or family was associated with well-being through both self-efficacy and self-esteem. However, social support derived from a significant other was solely linked with well-being through self-esteem. Drawing on attachment theory, close relationships with significant others can provide a generalized notion of worth as a person reflecting the experience of being valued by stable and important people in one's life (Harris \& Orth, 2019). Unexpectedly, social support derived from student peers was not associated with self-efficacy; this result could be caused by the student participants answering the self-efficacy scale regarding global beliefs in one's abilities to execute the necessary behavior in a given situation and not specifically related to academic self-efficacy (Zimmerman et al., 1992).

\section{Limitations}




\section{SOCIAL SUPPORT AND WELL-BING DURING COVID LOCKDOWN}

There are several important limitations to the present study that should be mentioned. First, the recruitment of participants through convenience sampling poses several limitations. For example, the use of Facebook can recruit participants with some degree of online social network involvement and social support; consequently, the results might not be broadly generalizable across students in Denmark who might experience less social support from not engaging with such social media groups. Second, although based on power analysis, the sample size in the present study was relatively small. A greater sample size might provide statistical power to detect small significant changes regarding, for example, perceived stress. Third, the analyses do not allow any directional or causal conclusions. For example, while social support appears to predict self-esteem in the results, this association might reflect how people experiencing a positive self-evaluation facilitate social relationships. In this regard, a meta-analysis found the association between social relationships and self-esteem to be truly reciprocal, reflecting a positive feedback loop (Harris \& Orth, 2019). Fourth, the measurements in the present study were self-reported, which might inflate the correlations among variables. Consequently, some caution should be employed when interpreting the results.

\section{Conclusion}

During the COVID-19 pandemic, societal lockdown has affected people's everyday life and consequently their well-being. Lockdown measures such as social distancing can challenge one's experience of social support, perception and sense of self, and one's psychological well-being. In the present study, there were no statistically significant changes in social support, self-efficacy, selfesteem, perceived stress, and life satisfaction among Danish student from the period of societal lockdown to the reopening of society. Moreover, social support derived from a significant person, family, and friends — but not student peers — was negatively linked with perceived stress and positively associated with life satisfaction through both self-efficacy and self-esteem. These associations were generally consistent across societal lockdown and reopening of society. These 


\section{SOCIAL SUPPORT AND WELL-BING DURING COVID LOCKDOWN}

results suggest that the students were not significantly affected by the lockdown or that a negative impact of lockdown requires more time to be alleviated. Either way, the results emphasize that social support emerges as an important resource for students' self-conception and well-being both during and after COVID-19 lockdown.

\section{References}

Arebela, I., Rojas-Ruiz, G., Granda-Vera, J., \& Mingorance-Estrada, Á. C. (2020). Influence of COVID-19 on the perception of academic self-efficacy, state anxiety, and trait anxiety in college students. Frontiers in psychology, 11 .

Aucejo, E. M., French, J., Araya, M. P. U., \& Zafar, B. (2020). The impact of COVID-19 on student experiences and expectations: Evidence from a survey. Journal of public economics, 191, 104271. https://doi.org/10.1016/j.jpubeco.2020.104271

Bartimote-Aufflick, K., Bridgeman, A., Walker, R., Sharma, M., \& Smith, L. (2016). The study, evaluation, and improvement of university student self-efficacy. Studies in Higher Education, 41(11), 1918-1942. https://doi.org/10.1080/03075079.2014.999319

Bandura, A. (1997). Self-efficacy: The exercise of control. W H Freeman/Times Books/ Henry Holt \& Co.

Callaghan, P., \& Morrissey, J. (1993). Social support and health: a review. Journal of advanced nursing, 18(2), 203-210.

Cassel, J. (1976). The contribution of the social environment to host resistance: The Fourth Wade Hampton Frost Lecture. American Journal of Epidemiology, 104(2), 107-123.

Cohen, S., Kamarck, T., \& Mermelstein, R. (1983). A global measure of perceived stress. Journal of Health and Social Behavior, 24(4), 385-396. doi: 10.2307/2136404.

de Sousa, G. M., Tavares, V., de Meiroz Grilo, M., Coelho, M., de Lima-Araújo, G. L., Schuch, F. B., \& Galvão-Coelho, N. L. (2021). Mental Health in COVID-19 Pandemic: A MetaReview of Prevalence Meta-Analyses. Frontiers in psychology, 12, 703838. https://doi.org/10.3389/fpsyg.2021.703838 


\section{SOCIAL SUPPORT AND WELL-BING DURING COVID LOCKDOWN}

Diener, E., Emmons R. A., Larsen, R. J., and Griffin, S. (1985). "The Satisfaction with Life Scale." Journal of Personality Assessment, 49(1), 71-75. doi: 10.1207/s15327752jpa4901_13.

Friedlander, L.J., Reid, G.J., Shupak, N., \& Cribbie, R. (2007). Social Support, Self-Esteem, and Stress as Predictors of Adjustment to University Among First-Year Undergraduates. Journal of College Student Development 48(3), 259-274. doi:10.1353/csd.2007.0024.

Harris, M. A., \& Orth, U. (2020). The link between self-esteem and social relationships: A metaanalysis of longitudinal studies. Journal of Personality and Social Psychology, 119(6), 1459-1477. doi:http://dx.doi.org/10.1037/pspp0000265

Kepes, S., Banks, G. C., \& Oh, I. S. (2014). Avoiding bias in publication bias research: The value of "null” findings. Journal of Business and Psychology, 29(2), 183-203. https://doi.org/10.1007/s10869-012-9279-0

Kline, R, B. (2015). Principles and practice of structural equation modeling. New York, US: Guilford Press.

Leary, M. R. (1999). Making sense of self-esteem. Current directions in psychological science, 8(1), 32-35. https://doi.org/10.1111/1467-8721.00008

Li, J., Han, X., Wang, W., Sun, G., \& Cheng, Z. (2018). How social support influences university students' academic achievement and emotional exhaustion: The mediating role of selfesteem. Learning and individual differences, 61, 120-126. https://doi.org/10.1016/j.lindif.2017.11.016

Li, Y., Peng, J., \& Tao, Y. (2021). Relationship between social support, coping strategy against COVID-19, and anxiety among home-quarantined Chinese university students: A path analysis modeling approach. Current Psychology, 1-16.

Mai, Y., Wu, Y. J., \& Huang, Y. (2021). What type of social support is important for student resilience during COVID-19? A latent profile analysis. Frontiers in Psychology, 12, 2463.

Moos, R. H. (1990). Coping Response Inventory Youth Form—Professional Manual. Odessa, Florida: PAR Psychological Assessment Resources, Inc.

Muthén, L. K., \& Muthén, B. O. (1998-2011). Mplus User's Guide. Sixth Edition. Los Angeles, US: Muthén \& Muthén. 


\section{SOCIAL SUPPORT AND WELL-BING DURING COVID LOCKDOWN}

Nieto, I., Navas, J. F., \& Vázquez, C. (2020). The quality of research on mental health related to the COVID-19 pandemic: A note of caution after a systematic review. Brain, behavior, \& immunity-health, 100123. https://doi.org/10.1016/j.bbih.2020.100123

O'Connor, R., Wetherall, K., Cleare, S., McClelland, H., Melson, A., Niedzwiedz, C., . . Robb, K. (2021). Mental health and well-being during the COVID-19 pandemic: Longitudinal analyses of adults in the UK COVID-19 Mental Health \& Wellbeing study. The British Journal of Psychiatry, 218(6), 326-333. doi:10.1192/bjp.2020.212

Odriozola-González, P., Planchuelo-Gómez, Á., Irurtia, M. J., \& de Luis-García, R. (2020). Psychological effects of the COVID-19 outbreak and lockdown among students and workers of a Spanish university. Psychiatry Research, $290,8$. http://doi.org/10.1016/j.psychres.2020.113108

Planchuelo-Gómez, Á., Odriozola-González, P., Irurtia, M. J., \& de Luis-García, R. (2020). Longitudinal evaluation of the psychological impact of the COVID-19 crisis in Spain. Journal of Affective Disorders, 277, 842-849. http://doi.org/10.1016/j.jad.2020.09.018

Rosenberg, M. (1965). Rosenberg self-esteem scale (RSE). Acceptance and commitment therapy. Measures package, 61(52), 18.

Rossi, A., Panzeri, A., Pietrabissa, G., Manzoni, G. M., Castelnuovo, G., \& Mannarini, S. (2020). The anxiety-buffer hypothesis in the time of COVID-19: when self-esteem protects from the impact of loneliness and fear on anxiety and depression. Frontiers in psychology, 11, 2177.

Saltzman, K. M., \& Holahan, C. J. (2002). Social support, self-efficacy, and depressive symptoms: An integrative model. Journal of Social and Clinical Psychology, 21(3), 309-322. https://doi.org/10.1521/jscp.21.3.309.22531

Shumaker, S. A., \& Brownell, A. (1984). Toward a theory of social support: Closing conceptual gaps. Journal of social issues, 40(4), 11-36.

Schermelleh-Engel, K., Moosbrugger, H., \& Müller, H. (2003). Evaluating the Fit of Structural Equation Models: Tests of Significance and Descriptive Goodness-of-Fit Measures. Methods of Psychological Research, 8(2), 23-74. 


\section{SOCIAL SUPPORT AND WELL-BING DURING COVID LOCKDOWN}

Schwarzer, R., \& Jerusalem, M. (1995). Generalized Self-Efficacy scale. In J. Weinman, S. Wright, \& M. Johnston, Measures in health psychology: A user's portfolio. Causal and control beliefs (pp. 35-37). Windsor, UK: NFER-NELSON.

Sibley, C. G., Greaves, L. M., Satherley, N., Wilson, M. S., Overall, N. C., Lee, C. H. J., Milojev, P., Bulbulia, J., Osborne, D., Milfont, T. L., Houkamau, C. A., Duck, I. M., Vickers-Jones, R., \& Barlow, F. K. (2020). Effects of the COVID-19 pandemic and nationwide lockdown on trust, attitudes toward government, and well-being. American Psychologist, 75(5), 618630. http://dx.doi.org/10.1037/amp0000662

Şimşir, Z., Koç, H., Seki, T., \& Griffiths, M. D. (2021) The relationship between fear of COVID-19 and mental health problems: A meta-analysis, Death Studies, DOI:

$10.1080 / 07481187.2021 .1889097$

Szkody, E., Stearns, M., Stanhope, L., \& McKinney, C. (2020). Stress-buffering role of social support during covid-19. Family Process, doi:http://dx.doi.org/10.1111/famp.12618

Thoits, P. A. (1985). Social support and psychological well-being: Theoretical possibilities. In Social support: Theory, research and applications (pp. 51-72). Springer, Dordrecht.

Wang, C., Pan, R., Wan, X., Tan, Y., Xu, L., McIntyre, R. S., . . Ho, C. (2020). A longitudinal study on the mental health of general population during the COVID-19 epidemic in China. Brain, Behavior, and Immunity, 87, 40-48. http://doi.org/10.1016/j.bbi.2020.04.028

World Health Organization. (2021). Coronavirus disease (COVID-19) advice for the public: Myth busters. URL: https://www. who. int/emergencies/diseases/novel-coronavirus-2019/advicefor-public/myth-busters [accessed 2021-12-10].

Xu, J., Ou, J., Luo, S., Wang, Z., Chang, E., Novak, C., ... \& Wang, Y. (2020). Perceived social support protects lonely people against COVID-19 anxiety: A three-wave longitudinal study in China. Frontiers in psychology, 11.

Zimet, G. D., Dahlem, N. W., Zimet, S. G., \& Farley, G. K. (1988). The multidimensional scale of perceived social support. Journal of Personality Assessment, 52(1), 30-41. doi: 2048/10.1207/s15327752jpa5201_2. 
SOCIAL SUPPORT AND WELL-BING DURING COVID LOCKDOWN

Zimmerman, B. J., Bandura, A., \& Martinez-Pons, M. (1992). Self-motivation for academic attainment: The role of self-efficacy beliefs and personal goal setting. American Educational Research Journal, 29(3), 663-676. doi:http://dx.doi.org/10.2307/1163261 